\title{
Environmental tobacco smoke exposure in the home and worksite and health effects in adults: results from the 1991 National Health Interview Survey
}

\author{
David M Mannino, Michael Siegel, Deborah Rose, John Nkuchia, Ruth Etzel
}

Air Pollution and Respiratory Health Branch, Division of Environmental Hazards and Health Effects, National Center for

Environmental Health, Centers for Disease Control and

Prevention, Atlanta,

Georgia, USA

D M Mannino

R Etzel

Boston University School of Public Health, Boston, Massachusetts M Siegel

Division of Health Interview Statistics, Office of Vital and Health Statistics Systems, National Center for Health Statistics, Centers for Disease Control and Prevention,

Hyattsville, Maryland

D Rose

Epidemiology Branch, Office on Smoking and Health, National

Center for Chronic

Disease Prevention and Health Promotion, Centers for Disease Control and Prevention, Atlanta, Georgia

J Nkuchia

Correspondence to:

Dr DM Mannino, National Center for Environmental Health, US Centers for Disease Control and Prevention (CDC) MS-F39, 4770 Buford Hwy NE; Atlanta, Georgia

Atlanta, Georgia

DMM6@cdc.gov

\begin{abstract}
Objective-To determine the effect of environmental tobacco smoke (ETS) exposure in the home and worksite on the health of adults in the United States.

Design-Cross-sectional survey.

Setting-Nationally representative population.
\end{abstract}

Participants-43 732 adults who completed the Health Promotion and Disease Prevention supplement in the 1991 National Health Interview Survey.

Main outcome measures-Rate of restricted activity, bed confinement, and work absence in the two weeks preceding the survey and self-reported health status among adults with and without exposure to ETS.

Results-We found that only $20.2 \%$ of never-smokers and $23.1 \%$ of former smokers reported exposure to ETS at home or work, whereas $87.2 \%$ of current smokers reported exposure to ETS. Among never-smokers, after adjusting for covariates, people who were exposed to ETS were more likely to report one or more days of restricted activity (relative risk $(R R)=1.27,95 \%$ confidence interval (CI) $=1.10$ to 1.46 ), one or more days of bed confinement $(R R=1.43,95 \% \mathrm{CI}=$ 1.19 to 1.73 ), and one or more days of work absence $(R R=1.33,95 \% \mathrm{CI}=1.05$ to 1.73$)$ in the two weeks before the survey than were people without such exposure. We detected smaller trends for one or more days of restricted activity among current and former smokers $(\mathrm{RR}=1.16,95 \% \mathrm{CI}=$ 0.97 to 1.40 ; and $R R=1.11,95 \% \mathrm{CI}=0.82$ to 1.51), one or more days of bed confinement among current smokers $(R R=1.34$, $95 \% \mathrm{CI}=0.95$ to 1.88 ), and one or more days of work absence among former smokers $(R R=1.13,95 \% \mathrm{CI}=0.84$ to 1.50$)$ in the two weeks before the survey than among people without such exposure, although the CIs were wide and chance cannot be excluded as an explanation for these findings. Never-smokers $(R R=1.47$, $95 \% \mathrm{CI}=1.34$ to 1.62 ), former smokers $(R R=1.22,95 \% C I=1.07$ to 1.39$)$ and current smokers $(R R=1.31,95 \% C I=$ 1.10 to 1.56) exposed to ETS were all more likely to report a less than very good health status than were people without such exposure.

Conclusions-This study demonstrates that never-smoking adults exposed to ETS report more acute health effects than unexposed, never-smoking adults, and suggests similar findings in current and former smoking adults.

(Tobacco Control 1997;6:296-305)

Keywords: adults, environmental tobacco smoke, respiratory tract diseases

\section{Introduction}

Environmental tobacco smoke (ETS) contains the same constituents that are known to cause respiratory disease in people who smoke. ${ }^{1}$ Many studies have demonstrated an association between ETS exposure and respiratory disease in both children ${ }^{2-5}$ and adults. ${ }^{6-8}$ In this study, we used data from the 1991 National Health Interview Survey (NHIS) to investigate the relationship between ETS exposure and acute illnesses in adults. The NHIS was conducted among a probability sample of the civilian, non-institutionalised population of the United States. ${ }^{9}$ It consists of an extensive questionnaire that asks participants about their present health status, including whether they have had any recent illnesses. The first year in which all participants were asked whether they were exposed to ETS in their homes was 1991. We determined the number of adults exposed to ETS either in their homes or worksites and compared morbidity data (days of restricted activity, bed confinement and work absence, self-reported health status, and exacerbations of chronic respiratory and cardiac diseases) for these adults with the corresponding data for adults not exposed to ETS.

\section{Methods}

We searched the 1991 NHIS database for all subjects aged 18 years and older who completed the Health Promotion and Disease Prevention supplement. All respondents were asked about their smoking history. We classified subjects as current smokers (currently smoking cigarettes every day or some days or currently smoking a pipe or cigars), former smokers (smoked at least 100 cigarettes in their life but not currently smoking), or never-smokers (never smoked more than 100 cigarettes in their life). Former smokers were asked how many years ago they 
stopped smoking, but not when they started smoking or how many cigarettes they smoked daily, and current smokers were asked how many cigarettes they smoked daily. Each subject was asked: "Does anyone smoke cigarettes, cigars, or pipes anywhere inside this home?" and "On the average, about how many days per week is there smoking anywhere inside this home?" People who were currently working and either had a private enclosed office with a door, a shared office with a door, a cubicle with full or mid-height partitions, or an open office area were asked: "During the past two weeks, has anyone smoked in your immediate work area?". This question was not asked of people who had no regular work area, worked outdoors, travelled to different worksites, or worked in a motor vehicle. We excluded subjects who did not respond to questions about their personal smoking history or ETS exposure in their home. We compared adults with no reported ETS exposure either at home or at work with those with any reported ETS exposure.

Respondents were asked to estimate the number of days they had to decrease their usual activity, were confined to bed, or were absent from work because of illness during the two weeks preceding the survey. Total restricted activity days are the unduplicated sum of work absence, bed confinement, and decreased activity days. We limited our analysis of days people were absent from work to adults age 65 years and younger who were currently working. We multiplied the number of days by 26 to obtain annual estimates. We also classified each person as having one or more versus no days of restricted activity, bed confinement, or work absence in the two weeks before the survey for use in logistic regression models.

Chronic diseases could be reported in three ways: in response to a chronic disease questionnaire, as a reason for a hospitalisation or physician visit in the two weeks before the survey, or as a reason for activity limitation in the two weeks before the survey. As part of the NHIS protocol, the total sample was divided into six subgroups, each of which was asked about a different group of chronic illnesses: musculoskeletal conditions, impairments, digestive conditions, neurological and endocrine conditions, circulatory conditions, and respiratory conditions. We searched for chronic bronchitis, asthma, chronic sinusitis, and emphysema within the respiratory conditions subgroup; and ischaemic heart disease, cerebrovascular disease, hardening of the arteries, and aneurysm within the circulatory conditions subgroup. To determine the prevalence of these conditions, one would have to restrict the sample to the one-sixth subgroup that was asked about either respiratory or circulatory conditions (not used in this study). We considered subjects who had activity limitation or a physician's visit in the two weeks preceding the survey because of one of the chronic diseases noted above to have an "exacerbation" of this disease. To determine the rate of exacerbations of these diseases in the two weeks preceding the survey, we limited the database to the people in approximately five-sixths of the sample who were not asked about chronic respiratory diseases or cardiovascular diseases.

The core NHIS contained the question: "Would you say your health in gene $\vec{\Rightarrow}$ il is excellent, very good, good, fair, or poor? fied the responses into two groups.్ㅡㄹ gory good and better, and good and worse.

We classified people as having lower socioeconomic status if they were fom a family in which the total family income-was below the 1990 poverty level (as derived from the August 1991 Current Population Subjuey) ${ }^{10}$ and calculated on the basis of family sich, number of children less than 18 years old, and family income, or if they had a 12th gifade (high school) education or less. We exclued adults for whom data on poverty status or eglucational level was missing. In all of our regression analyses and our determination $\overrightarrow{0 f}$ national population estimates we used hHIS weights. We age-adjusted the data $\$$ figures to the age distribution of ghe entire study sample because the age distribution of current, former and never smokers

Because the NHIS is a complex sample design, we used SUDAAN (RTI, Resegegch Triangle Park, North Carolina) to לlletermine variances and to do significance tes $\overline{\text { gn }}$ g in our regression models. The point oestimates obtained with SUDAAN are identica $\$$ obtained with SAS (SAS Institute, Cäry, North Carolina), whereas the variances are larger with SUDAAN because SUDAAN, unlike SAS, accounts for the complex sample design of the NHIS survey. We used the SAS procgdure GLM to calculate Bonferroni $t$ tests for diffences of mean exposures to ETS for region, soason, and work status. We used the SUDAAN grocedures RLOGIST (logistic regression), REGRE regression), CROSSTAB, and DESCRIPT⿱㇒ In these analyses. We also used the sAS rocedure LOGISTIC to model the number of days of restricted activity, bed confinement, 3and work absence in a Poisson regression. The point estimates we obtained using this weressimilar to those obtained using the SUDAAN Trocedure REGRESS, although the variances were smaller, and we only present the linear - Pegression results. In the logistic and linear regressions we included socioeconomic status, sex, cpeople in household (living alone or not livifg alone), region of country, race, season dufing which the questionnaire was completed, ब,ge, work status (working and asked about ET $\$$ exposure at work, working and not asked agout ETS

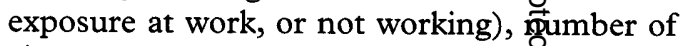
cigarettes smoked daily among smakers, and years ago they stopped smoking among former smokers, as potential covariates ând effect modifiers. In our preliminary gegression models we analysed data on all partienpants for whom we had complete data, to detemine the effect of current and former smoking on our outcome measures. In our final models, we ran separate analyses on never-smokers, former smokers, and current smokers. 
Table 1 Study population of adults, age 18 and older, stratified by smoking status and reported environmental tobacco smoke (ETS) exposure at home and at work, from the 1991 National Health Interview Survey. The national estimates of these populations and the weighted percentages (WP) are also presented (columns may not add up to $100 \%$ beccause of rounding)

\begin{tabular}{|c|c|c|c|c|c|c|c|c|c|c|c|c|}
\hline \multirow[b]{2}{*}{ ETS exposure } & \multicolumn{3}{|c|}{ Current smokers } & \multicolumn{3}{|c|}{ Former smokers } & \multicolumn{3}{|c|}{ Never-smokers } & \multicolumn{3}{|c|}{ Total } \\
\hline & Number & $\begin{array}{l}\text { Estimated } \\
\text { national } \\
\text { population }\end{array}$ & $W P$ & Number & $\begin{array}{l}\text { Estimated } \\
\text { national } \\
\text { population }\end{array}$ & $W P$ & Number & $\begin{array}{l}\text { Estimated } \\
\text { national } \\
\text { population }\end{array}$ & $W P$ & Number & $\begin{array}{l}\text { Estimated } \\
\text { national } \\
\text { population }\end{array}$ & $W P$ \\
\hline Home: unknown & 210 & 897000 & 1.9 & 80 & 345000 & 0.7 & 187 & 798000 & 0.9 & 477 & 2040000 & 1.1 \\
\hline $\begin{array}{l}\text { Home: no; work: } \\
\text { no }\end{array}$ & 1139 & 5259000 & 10.9 & 7429 & 30559000 & 76.1 & 17021 & 68943000 & 78.9 & 25589 & 104761000 & 59.6 \\
\hline $\begin{array}{l}\text { Home: no; work: } \\
\text { yes }\end{array}$ & 97 & 454000 & 0.9 & 349 & 1472000 & 3.7 & 724 & 3159000 & 3.6 & 1170 & 5085000 & 2.8 \\
\hline $\begin{array}{l}\text { Home: < daily; } \\
\text { work: no }\end{array}$ & 842 & 3119000 & 6.4 & 491 & 1875000 & 4.7 & 921 & 3600000 & 4.1 & 2254 & 8594000 & 4.8 \\
\hline $\begin{array}{l}\text { Home: <daily; } \\
\text { work: yes }\end{array}$ & 64 & 257000 & 0.5 & 30 & 109000 & 0.2 & 45 & 188000 & 0.2 & 139 & 554000 & 0.3 \\
\hline $\begin{array}{l}\text { Home: daily; work: } \\
\text { no }\end{array}$ & 8633 & 35576000 & 73.4 & 1075 & 5503000 & 13.7 & 1900 & 9995000 & 11.5 & 11608 & 51074000 & 29.0 \\
\hline $\begin{array}{l}\text { Home: daily; work: } \\
\text { yes }\end{array}$ & 716 & 2935000 & 6.0 & 58 & 321000 & 0.7 & 104 & 584000 & 0.7 & 878 & 3840000 & 2.3 \\
\hline $\begin{array}{l}\text { Total: any ETS } \\
\text { exposure }\end{array}$ & 10352 & 42341000 & 87.2 & 2003 & 9280000 & 23.1 & 3694 & 17526000 & 20.2 & 16049 & 69147000 & 39.2 \\
\hline Total & 11701 & 48497000 & & 9512 & 40184000 & & 20902 & 87267000 & & 42115 & 175948000 & \\
\hline
\end{tabular}

Table excludes 569 participants (representing 2715000 people) who did not have a smoking status listed and 1048 participants (representing 4528000 people) for whom we could not classify a socioeconomic status.

\section{Results}

We analysed data on 43732 adults, representing an estimated 183 million American adults aged 18 years and older, who completed the Health Promotion and Disease Prevention supplement in 1991. After we excluded 569 participants who did not have a smoking status listed and 1048 participants for whom we could not classify a socioeconomic status, our database contained 42115 people (table 1). We further excluded 477 people who had unknown ETS exposure at home and were left with 41638 participants. On the basis of these data, we estimate that 69.1 million adults (39.8\%, weighted percentage (WP)) were exposed to ETS in their homes or worksites (table 1). The percentage of people exposed varied dramatically by smoking status; only $20.2 \%$ (WP) of never-smokers and $23.1 \%$ (WP) of former smokers reported ETS exposure whereas $87.2 \%$ (WP) of current smokers did so (table 1). Of the participants reporting less-than-daily ETS exposure in the home, $20.6 \%$ (WP) reported being exposed four to six days weekly, $45.7 \%$ (WP) reported being exposed one to three days weekly, and $33.7 \%$ (WP) reported being exposed less than a day a week.

Of the people in our final dataset, $49.7 \%$ (WP) were never-smokers, $22.9 \%$ (WP) were former smokers, and $27.4 \%$ (WP) were current smokers. The median age of the never-smokers and current smokers in the study was 39 years, whereas the median age of the former smokers was 52 years. Of the former smokers, $28.6 \%$ (WP) had stopped smoking more than 15 years before the survey, $31.3 \%$ (WP) had stopped smoking 5-15 years before the survey, 22.2\% (WP) had stopped smoking one to five years before the survey, and the remaining $17.9 \%$ (WP) had either stopped smoking in the year before the survey or did not answer this question.

Among adults under the age of $65,25.9 \%$ (WP, age-adjusted) of never-smokers, $24.4 \%$ (WP, age-adjusted) of former smokers, and $28.3 \%$ (WP, age-adjusted) of current smokers were currently not employed. After adjusting for age, sex, season, region, socioeconomic status and race, current smokers were more likely to be not employed (relative risk $=1.33,95 \%$ confidence interval $=1.22$ to 1.45 ) than were never-smokers.

Among never-smokers, the rate of ETS exposure in the home or worksite varied significantly by socioeconomic status, race, living alone, and age (table 2). These same variables, along with sex, and years ago stopped smoking or number of cigarettes smoked daily, were related to the rate of ETS exposure among current and former smokers (tables 3 and 4). Among current, former, and never-smokers, people in the west region of the United States reported less ETS exposure ( $\mathrm{P}<0.05$ for all, by Bonferroni $t$ tests). Among former and never-smokers, people working and asked about ETS exposure reported more ETS exposure than among people working and not asked about ETS exposure or among people not working $(\mathrm{P}<0.05$ for all, by Bonferroni $t$ tests). We did not detect any significant difference in this measure among current smokers, nor did we detect any significant seasonal difference in ETS exposure in any smoking category ( $\mathrm{P}>0.05$ for all, by Bonferroni $t$ tests).

One or more restricted activity days in the two weeks before the survey was reported by 9.4\% (WP, age-adjusted) of never-smokers, $10.4 \%$ (WP, age-adjusted) of former smokers, and $11.7 \%$ (WP, age-adjusted) of current smokers (figure 1). One or more days of bed confinement in the two weeks before the survey was reported by $4.9 \%$ (WP, age-adjusted) of never-smokers, $5.5 \%$ (WP, age-adjusted) of former smokers, and $6.3 \%$ (WP, age-adjusted) of current smokers (figure 1). Among workers under the age of 65 , one or more days of work absence in the two weeks before the survey was reported by $5.3 \%$ (WP, age-adjusted) of neversmokers, $6.0 \%$ (WP, age-adjusted) of former smokers, and $6.4 \%$ (WP, age-adjusted) of current smokers (figure 2). In the logistic regression models, in which we determined the chance of people reporting one or more days of 
restricted activity, bed confinement, or work absence in the two weeks before the survey, never-smokers exposed to ETS reported significantly more morbidity than unexposed never-smokers (table 5). These finfings were consistent before and after adjưsting for

Table 2 Study population of never-smoking adults, age 18 and older, stratified by socioeconomic status (SES) family size, region of country, season, age, and smoking status, with the number and weighted percentage (WP 0 f adults in each category (by row) with any reported exposure and no reported exposure to environmental tobacco smoke (ETS), from the 1991 National Health Interview Survey

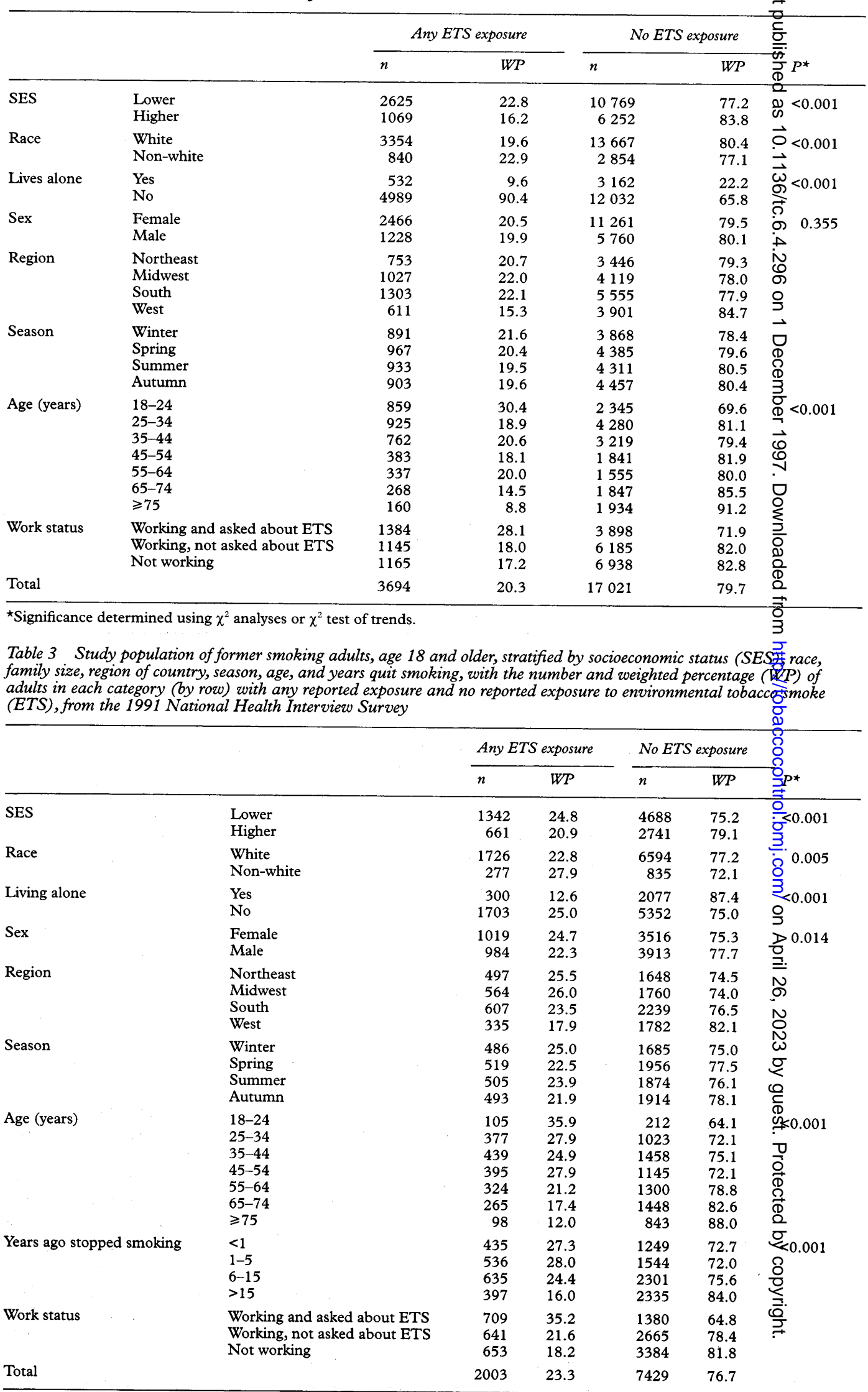

^Significance determined using $\chi^{2}$ analyses or $\chi^{2}$ test of trends. 
Table 4 Study population of smoking adults, age 18 and older, stratified by socioeconomic status (SES), race, family size, region of country, season, age, and cigarettes smoked daily, with the number and weighted percentage (WP) of adults in each category (by row) with any reported exposure and no reported exposure to environmental tobacco smoke (ETS), from the 1991 National Health Interview Survey

\begin{tabular}{|c|c|c|c|c|c|c|}
\hline & & \multicolumn{2}{|c|}{ Any ETS exposure } & \multicolumn{2}{|c|}{ No ETS exposure } & \multirow[b]{2}{*}{$P^{*}$} \\
\hline & & $n$ & $W P$ & $\bar{n}$ & $W P$ & \\
\hline SES & $\begin{array}{l}\text { Lower } \\
\text { Higher }\end{array}$ & $\begin{array}{l}8084 \\
2268\end{array}$ & $\begin{array}{l}90.9 \\
83.1\end{array}$ & $\begin{array}{l}725 \\
414\end{array}$ & $\begin{array}{r}9.1 \\
16.9\end{array}$ & $<0.001$ \\
\hline Race & $\begin{array}{l}\text { White } \\
\text { Non-white }\end{array}$ & $\begin{array}{l}8339 \\
2013\end{array}$ & $\begin{array}{l}88.6 \\
90.5\end{array}$ & $\begin{array}{l}952 \\
187\end{array}$ & $\begin{array}{r}11.4 \\
9.5\end{array}$ & 0.023 \\
\hline Living alone & $\begin{array}{l}\text { Yes } \\
\text { No }\end{array}$ & $\begin{array}{l}2658 \\
7964\end{array}$ & $\begin{array}{l}92.9 \\
88.3\end{array}$ & $\begin{array}{l}198 \\
941\end{array}$ & $\begin{array}{r}7.1 \\
11.7\end{array}$ & $<0.001$ \\
\hline Sex & $\begin{array}{l}\text { Female } \\
\text { Male }\end{array}$ & $\begin{array}{l}5502 \\
4850\end{array}$ & $\begin{array}{l}92.1 \\
86.3\end{array}$ & $\begin{array}{l}436 \\
703\end{array}$ & $\begin{array}{r}7.9 \\
13.7\end{array}$ & $<0.001$ \\
\hline Region & $\begin{array}{l}\text { Northeast } \\
\text { Midwest } \\
\text { South } \\
\text { West }\end{array}$ & $\begin{array}{ll}2 & 084 \\
2 & 812 \\
3 & 545 \\
1 & 991\end{array}$ & $\begin{array}{l}89.9 \\
91.2 \\
90.9 \\
81.8\end{array}$ & $\begin{array}{l}208 \\
257 \\
310 \\
364\end{array}$ & $\begin{array}{r}10.1 \\
8.8 \\
9.1 \\
18.2\end{array}$ & \\
\hline Season & $\begin{array}{l}\text { Winter } \\
\text { Spring } \\
\text { Summer } \\
\text { Autumn }\end{array}$ & $\begin{array}{ll}2 & 551 \\
2 & 626 \\
2 & 570 \\
2 & 605\end{array}$ & $\begin{array}{l}90.4 \\
88.5 \\
87.5 \\
89.3\end{array}$ & $\begin{array}{l}238 \\
305 \\
317 \\
279\end{array}$ & $\begin{array}{r}9.6 \\
11.5 \\
12.5 \\
10.7\end{array}$ & \\
\hline Age (years) & $\begin{array}{l}18-24 \\
25-34 \\
35-44 \\
45-54 \\
55-64 \\
65-74 \\
\geqslant 75\end{array}$ & $\begin{array}{rr} & 996 \\
2 & 796 \\
2 & 565 \\
1 & 704 \\
1 & 196 \\
806 \\
\\
& 329\end{array}$ & \begin{tabular}{l|l|}
84.6 & \\
88.6 & 88.8 \\
91.5 \\
91.6 \\
88.6 \\
87.5
\end{tabular} & $\begin{array}{r}168 \\
312 \\
280 \\
153 \\
98 \\
88 \\
40\end{array}$ & $\begin{array}{r}15.4 \\
11.4 \\
11.2 \\
8.5 \\
8.4 \\
11.4 \\
12.5\end{array}$ & $<0.001$ \\
\hline Cigarettes smoked daily & $\begin{array}{l}\leqslant 10 \\
11-20 \\
20-30 \\
>30\end{array}$ & $\begin{array}{ll}3 & 746 \\
4 & 371 \\
1 & 212 \\
1 & 023\end{array}$ & $\begin{array}{l}79.9 \\
93.8 \\
96.6 \\
97.1\end{array}$ & $\begin{array}{r}829 \\
243 \\
41 \\
26\end{array}$ & $\begin{array}{r}20.1 \\
6.2 \\
3.4 \\
2.9\end{array}$ & $<0.001$ \\
\hline Work status & $\begin{array}{l}\text { Working and asked about ETS } \\
\text { Working, not asked about ETS } \\
\text { Not working }\end{array}$ & $\begin{array}{l}2193 \\
4509 \\
3650\end{array}$ & $\begin{array}{l}88.9 \\
87.8 \\
90.7\end{array}$ & $\begin{array}{l}244 \\
555 \\
340\end{array}$ & $\begin{array}{r}11.1 \\
12.2 \\
9.3\end{array}$ & \\
\hline Total & & 10352 & 88.9 & 1139 & 11.1 & \\
\hline
\end{tabular}

${ }^{\star}$ Significance determined using $\chi^{2}$ analyses or $\chi^{2}$ test of trends.

covariates (table 5). The corresponding fully adjusted models for current and former smokers all had confidence intervals that included

Table 5 The odds ratios of any restricted activity, bed confinement, work absence, exacerbations of chronic respiratory disease, and exacerbation of chronic cardiovascular disease, in the two weeks before the survey, among current, former, and never-smoking adults exposed to environmental tobacco smoke (ETS), compared with adults without such exposure. This table also displays the odds ratios for less than very good health status. Odds ratios are shown after adjusting for age only and after adjusting for age, socioeconomic status, race, living alone, sex, season, smoking status, region of country, cigarettes smoked daily (among current smokers), and years ago quit smoking (among former smokers), using logistic regression. From the 1991 National Health Interview Survey

\begin{tabular}{|c|c|c|c|c|}
\hline & \multicolumn{2}{|c|}{ Adjusted for age } & \multicolumn{2}{|c|}{ Adjusted for all covariates } \\
\hline & $\begin{array}{l}\text { Odds } \\
\text { ratio }\end{array}$ & $95 \% C I$ & $\underset{\text { ratio }}{\text { Odds }}$ & $95 \% C I$ \\
\hline \multicolumn{5}{|l|}{ Any restricted activity } \\
\hline Current smokers & 1.23 & $0.92-1.64$ & 1.11 & $0.82-1.51$ \\
\hline Former smokers & 1.13 & $0.95-1.35$ & 1.16 & $0.97-1.40$ \\
\hline Never-smokers & 1.23 & $1.07-1.41$ & 1.27 & $1.10-1.46$ \\
\hline \multicolumn{5}{|l|}{ Any bed confinement } \\
\hline Current smokers & 1.53 & $1.10-2.12$ & 1.34 & $0.95-1.88$ \\
\hline Former smokers & 1.00 & $0.78-1.29$ & 1.02 & $0.79-1.32$ \\
\hline Never-smokers & 1.41 & $1.17-1.70$ & 1.43 & $1.19-1.73$ \\
\hline \multicolumn{5}{|c|}{ Any work absence (among workers) } \\
\hline Current smokers & 1.08 & $0.74-1.58$ & 0.99 & $0.66-1.47$ \\
\hline Former smokers & 1.16 & $0.86-1.57$ & 1.13 & $0.84-1.50$ \\
\hline Never-smokers & 1.31 & $1.05-1.64$ & 1.33 & $1.05-1.68$ \\
\hline \multicolumn{5}{|c|}{ Any chronic respiratory disease exacerbation } \\
\hline Current smokers & 1.41 & $0.80-2.47$ & 1.33 & $0.77-2.29$ \\
\hline Former smokers & 0.89 & $0.62-1.28$ & 0.87 & $0.60-1.26$ \\
\hline Never-smokers & 1.42 & $1.05-1.91$ & 1.44 & $1.07-1.95$ \\
\hline \multicolumn{5}{|c|}{ Any chronic cardiovascular disease exacerbation } \\
\hline Current smokers & 1.44 & $0.53-3.95$ & 1.25 & $0.41-3.79$ \\
\hline Former smokers & 1.26 & $0.90-1.77$ & 1.23 & $0.86-1.77$ \\
\hline Never-smokers & 1.27 & $0.81-2.00$ & 1.21 & $0.75-1.94$ \\
\hline \multicolumn{5}{|c|}{ Less than very good health status } \\
\hline Current smokers & 1.66 & $1.41-1.97$ & 1.31 & $1.10-1.57$ \\
\hline Former smokers & 1.27 & $1.13-1.43$ & 1.22 & $1.07-1.39$ \\
\hline Never-smokers & 1.56 & $1.43-1.70$ & 1.47 & $1.34-1.62$ \\
\hline
\end{tabular}

unity; thus, chance cannot be excluded as an explanation for these findings (table 5).

In the linear regression models, after adjusting for age and for all covariates, we found that current, former, and never-smokers who were exposed to ETS reported more days of restricted activity and bed confinement than unexposed people in the same smoking category, although the confidence intervals were wide for most of these findings, and chance cannot be excluded as a explanation (table 6). Former and never-smoking workers under age 65 who were exposed to ETS reported more days of work absence than workers not exposed, whereas smoking workers exposed to ETS reported fewer days of work absence than smoking workers not exposed (table 6), but again the confidence intervals were wide, and chance cannot be excluded as an explanation for these findings.

Exacerbations of chronic respiratory diseases in the two weeks preceding the survey were reported by $1.8 \%$ (WP, age-adjusted) of never-smokers, $2.6 \%$ (WP, age-adjusted) of former smokers, and $2.7 \%$ (WP, age-adjusted) of current smokers (figure 3). Exacerbations of chronic cardiovascular disease in the two weeks preceding the survey were reported by $1.3 \%$ (WP, age-adjusted) of never-smokers, $2.9 \%$ (WP, age-adjusted) of former smokers, and $2.0 \%$ (WP, age-adjusted) of current smokers (figure 3). In the age-adjusted and fully adjusted regression models, current and neversmokers exposed to ETS reported more 


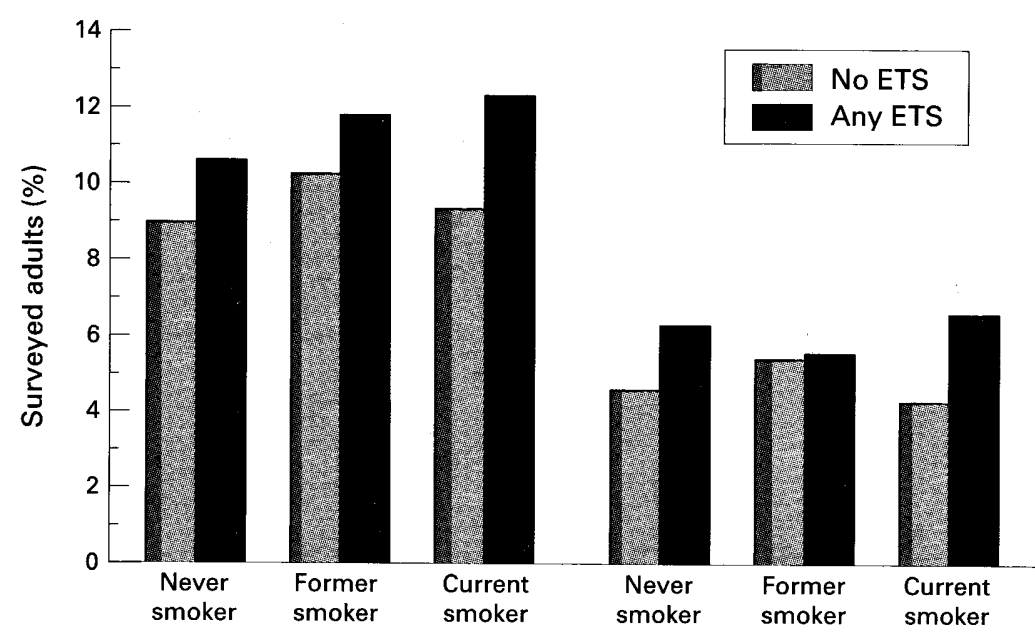

Any restricted activity day Any bed confinement day

Figure 1 The age-adjusted, weighted percentage of never-smokers, former smokers, and current smokers, exposed and not exposed to environmental tobacco smoke, who reported any day of restricted activity or bed confinement during the two weeks preceding the survey. From the 1991 National Health Interview Survey.

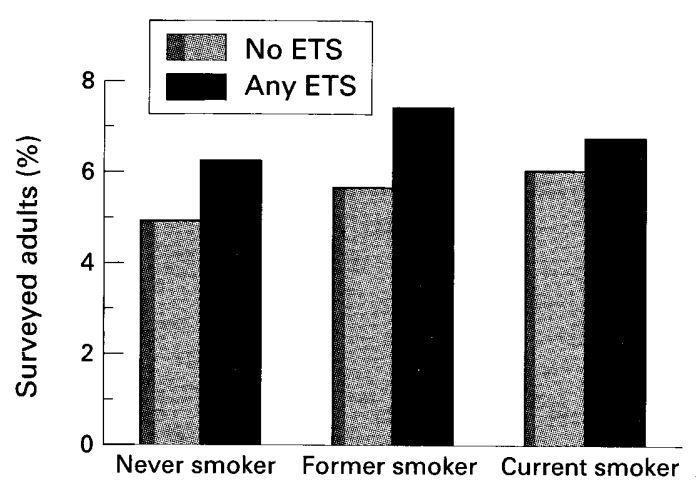

Any work absence day

Figure 2 The age-adjusted, weighted percentage of currently working never-smokers, former smokers, and current smokers, both exposed and not exposed to environmental tobacco smoke, who reported any day of work absence during the two weeks preceding the survey. From the 1991 National Health Interview Survey.

exacerbations of chronic respiratory diseases, whereas former smokers exposed to ETS reported fewer exacerbations of respiratory diseases; these findings reached significance only in never-smokers (table 5). Among current, former, and never-smokers, people exposed to ETS reported more exacerbations of cardiovascular disease in the two weeks before the survey than people withbut such exposure (figure 3). After adjusting कor covariates, we found that in all three smokifg categories, people exposed to ETS repozited more exacerbations of cardiovascular $\%$ disease, although again the confidence inte wide and included unity (table 5 ).

A very good or better health reported by $66.3 \%$ (WP, age-adisted) of never-smokers, $65.5 \%$ (WP, age-adiusted) of former smokers, and $56.6 \%$ (P, ageadjusted) of current smokers. Currefft, former, and never-smokers who were exposed to ETS in the home or worksite were all more likely to report that their health status was gless than very good, than were the unexposedppeople in the same smoking categories, both before and after adjusting for covariates (table 5 is

\section{Discussion}

Environmental tobacco smoke exposure is ubiquitous in the United States. Res recent nationally representative stuge ${ }^{11}$ show that $89 \%$ of people in the United Stertes age 6 or older had levels of cotinine in their blood greater than $5 \mathrm{ng} / \mathrm{dl}$. The percentage $\mathrm{f}$ American children exposed to ETS in the home has decreased from $62 \%$ in 1970 to $37 \%$ in $1991 .^{12}{ }^{13}$ This decrement is probablyorelated to the decreasing prevalence of smokifg among American adults. ${ }^{14}$ We do not have giationally representative historical data for ET\$ exposure among adults, but a 1963 study of adults in Washington County, Maryland, sh $\overrightarrow{\vec{g}} w e d$ that $30 \%$ of never-smoking men and $64 \%$ of neversmoking women were exposed to ETS at home, ${ }^{15}$ which is higher than the reported combined rates of ETS exposure (at $\overrightarrow{\mathrm{g}}$ ome and at work) of $20.5 \%$ among neves smoking women and $19.9 \%$ among never-sm\&king men that we detected in our study. The rêasons for these decreasing rates of exposure to ETS include the decreasing prevalence of smoking in the American population, ${ }^{14}$ the $\underline{\text { mineasing }}$ numbers of worksites that have restricted or eliminated smoking, ${ }^{16}$ and the number of communities in the United States that have enacted ordinances restricting or eliminating smoking in public placest?

Table 6 The increased number of days annually of restricted activity, bed confinement, and work absence among and current, former, and never-smoking adults exposed to environmental tobacco smoke (ETS), compared with adulis without such exposure, after adjusting for age only and after adjusting for age, socioeconomic status, race, living alone, sqe season, smoking status, region of country, cigarettes smoked daily (among current smokers), and years ago quit smoking (among former smokers), using linear regression, and the total mean annual days of restricted activity, bed confinement absence among both current non-smoking and current smoking adults. From the 1991 National Health Intervigos Survey

\begin{tabular}{|c|c|c|c|c|c|}
\hline & \multicolumn{2}{|c|}{ Adjusted for age } & \multicolumn{2}{|c|}{ Adjusted for all covariates } & \multirow{2}{*}{ 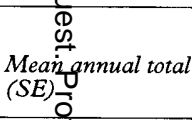 } \\
\hline & Days annually & $95 \% C I$ & Days annually & $95 \% C I$ & \\
\hline \multicolumn{5}{|c|}{ Days of restricted activity } & D \\
\hline Current smokers & 6.70 & $2.01-11.38$ & 4.22 & $-0.72-9.16$ & 20.4 (ర).7) \\
\hline Former smokers & 2.12 & $-1.86-6.10$ & 3.15 & $-1.00-7.30$ & $20.9(0.9)$ \\
\hline Never-smokers & 2.29 & $-0.66-5.24$ & 2.87 & $-0.13-5.87$ & $14.6 \$ 0.6)$ \\
\hline \multicolumn{5}{|c|}{ Days of bed confinement } & 0.01 \\
\hline Current smokers & 3.79 & $1.63-5.94$ & 2.63 & $0.04-5.22$ & $7.890 .5)$ \\
\hline Former smokers & 0.23 & $-2.20-2.66$ & 0.57 & $-1.94-3.08$ & $7.7 \$ 0.5)$ \\
\hline Never-smokers & 1.58 & $-0.28-3.44$ & 1.68 & $-0.22-3.58$ & $5.5 \$ 0.4)$ \\
\hline \multicolumn{5}{|c|}{ Days of work absence (among workers) } & \\
\hline Current smokers & -0.62 & $-4.36-3.12$ & -0.83 & $-4.71-3.05$ & $6.9 \overrightarrow{(0.4)}$ \\
\hline Former smokers & 0.54 & $-1.95-3.03$ & 0.99 & $-1.64-3.61$ & $6.2(0.6)$ \\
\hline Never-smokers & 0.48 & $-0.98-3.46$ & 0.75 & $-0.75-2.25$ & $4.8(0.3)$ \\
\hline
\end{tabular}

$\mathrm{CI}=$ confidence intervals. 


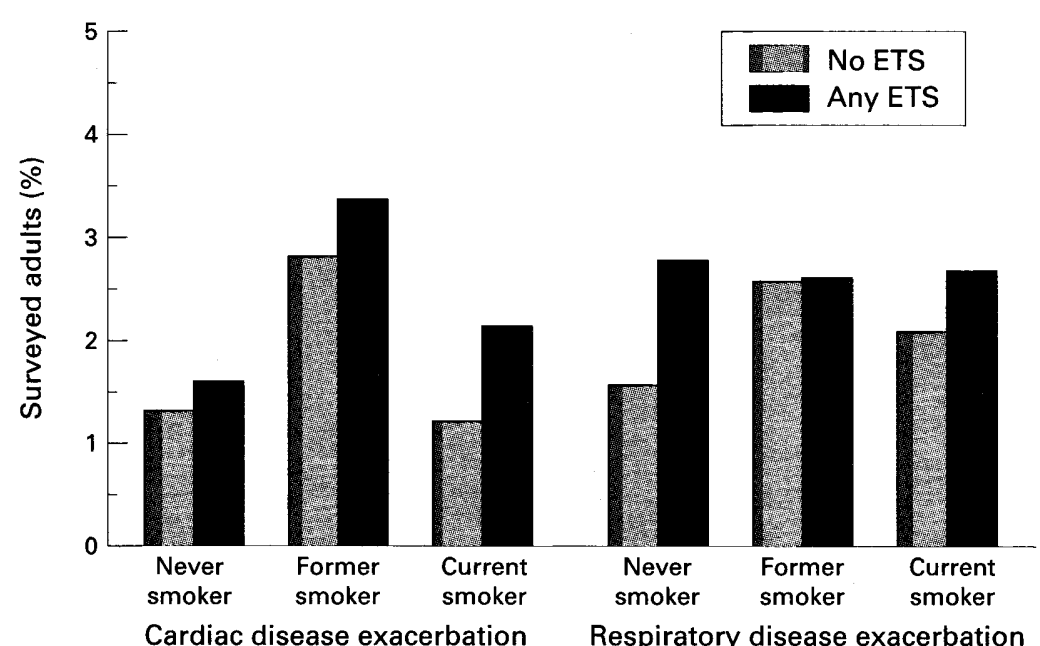

Figure 3 The age-adjusted, weighted percentage of never-smokers, former smokers, and current smokers, exposed and not exposed to environmental tobacco smoke, who reported any exacerbation of chronic cardiac disease or chronic respiratory disease during the two weeks preceding the survey. From the 1991 National Health Interview Survey.

We found that ETS exposure in the home or worksite varied dramatically by smoking status. Among current non-smokers (combining former and never-smokers) only $21.2 \%$ were exposed to ETS. This exposure rate is about half of that for children aged 1-10 from the same survey $(37.0 \%) .^{13}$ The most likely explanation for non-smoking adults having a lower rate of in-home ETS exposure than children is that adults can choose where to live and whom to live with, whereas children cannot. Fifteen per cent of the non-smoking adults in this survey lived alone, and many others chose to live with other non-smokers or to prohibit smoking in their homes. Conversely, among current smokers, $88.9 \%$ reported that they are exposed to ETS in their homes or worksites daily. Surprisingly, however, $12.0 \%$ of current smokers reported no ETS exposures in their home, indicating that neither they nor anyone else smokes in their homes.

Our primary finding in this study was increased morbidity, as measured by an increased rate of restricted activity, bed confinement, and work absence in the two weeks preceding the survey, among neversmokers exposed to ETS than among never-smokers not exposed to ETS. We also found that current, former, and never-smokers who were exposed to ETS classified themselves as being less healthy than those without this exposure. The relative risk we obtained for any restricted activity day in the two weeks preceding the survey $(1.27,95 \% \mathrm{CI}=1.10$ to 1.46$)$ is similar to the results we detected in children $(\mathrm{RR}=1.26,95 \% \mathrm{CI}=1.09 \text { to } 1.45)^{13}$ and the $20 \%$ increase in respiratory restricted days detected in a previous study of adults. ${ }^{19}$ The biological mechanism by which ETS causes respiratory illness in healthy adults is thought to be comparable with that of active light smoking, ${ }^{20}$ and people with a history of atopy or respiratory illness have been shown to be more sensitive to acute effects of ETS. ${ }^{21} \mathrm{~A}$ longitudinal study of student nurses demonstrated that ETS exposure was associated with an increased risk of phlegm production $(\mathrm{RR}=$ $1.41,95 \% \mathrm{CI}=1.08$ to 1.85$).^{22}$

Rates of restricted activity, bed confinement, and work absence in the two weeks preceding the survey among current and former smokers exposed to ETS were not significantly increased compared with those among current and former smokers not exposed to ETS. One explanation for these findings may be related to the smaller sample of current and former smokers compared with never-smokers, although it is possible that current and former smokers are less sensitive to ETS. Among smokers, evaluation of work absence days is probably influenced by smokers being more likely to be not working, compared with former and never-smokers, especially if working smokers represent a healthier subset of all smokers. In addition, all estimates of the effect of ETS exposures on the increased number of days of restricted activity, bed confinement, and work absence, except for days of bed confinement among current smokers, had wide confidence intervals. These wide confidence intervals are related to the sample size, the low prevalence of exposures and outcomes, and the influence of the design effect.

After adjusting for covariates, we found that current, former, and never-smokers who were exposed to ETS were more likely to have reported an exacerbation of chronic cardiovascular disease in the two weeks preceding the survey than those not exposed to ETS. In all of the adjusted models, confidence intervals included unity and chance cannot be ruled out as an explanation for these findings. ETS exposure among never-smokers has been linked to both atherosclerosis ${ }^{23}$ and ischaemic heart disease mortality. ${ }^{25}$ ETS exposure has also been linked to acute cardiovascular effects, thought to be related to increased platelet aggregation and increased oxygen demand by the heart. ${ }^{26}$ Clinical studies have demonstrated that ETS exposure exacerbates the symptoms of chronic cardiovascular disease. ${ }^{27-31}$ Increased carboxyhemoglobin levels resulting from passive smoking aggravate symptoms of angina by reducing myocardial oxygen delivery and decreasing contractility of the heart, ${ }^{28}{ }^{30}$ and they also impair exercise performance among patients with chronic obstructive pulmonary disease by reducing the lung's ability to oxygenate the blood. ${ }^{31}$ Nicotine and other ETS components may further aggravate angina in patients with heart disease. ${ }^{29}$ Most of the subjects in these clinical studies were ex-smokers or never-smokers; however, in the one study that included current smokers, ${ }^{29}$ a decrease in time to exerciseinduced angina was observed for all subjects, regardless of smoking status.

We also found that current and neversmokers, but not former smokers, who were exposed to ETS were more likely to have reported an exacerbation of chronic respiratory disease in the two weeks preceding the survey than those not exposed to ETS. This finding was significant only among never-smokers. An unexpected finding was that former smokers exposed to ETS did not report more 
exacerbations of chronic respiratory disease. Because we did not have information of duration of disease or prior ETS exposure, we cannot determine whether or not some subjects altered their ETS exposure as a potential explanation for this finding. There is both epidemiological and clinical evidence that ETS exposure may increase the risk of respiratory disease and aggravate symptoms of preexisting chronic respiratory disease among both non-smokers and smokers. Although many epidemiological studies have detected an increased risk for lung cancer among non-smokers exposed to ETS, ${ }^{132}$ several studies have also reported an increased risk for lung cancer among smokers who were exposed to ETS in the home, ${ }^{25}$ 33-36 although two studies did not find such an association. ${ }^{37} 38$ None of the study results were statistically significant ${ }^{39}$; however, meta-analyses of these studies reported significant pooled odds ratios of $1.3^{39}$ and $1.25 .{ }^{1}$ Because only two studies controlled for intensity of active smoking, ${ }^{25} 37$ confounding by amount smoked may explain these findings. Recent studies have also linked ETS exposure among non-smoking adults to obstructive respiratory disease and symptoms such as dyspnoea and bronchitis, ${ }^{20} 2240$ acute worsening of respiratory diseases, ${ }^{41}$ and increased symptoms of asthma. ${ }^{6}$

It is biologically plausible that the ETS exposure could increase the health risks of smokers as well as non-smokers. The levels of many toxic and carcinogenic chemicals are substantially higher in concentrated sidestream smoke than in concentrated mainstream smoke, although the overall ambient levels are lower because sidestream smoke is typically diluted into a larger airspace..$^{26}$ For example, the concentrations of the carcinogens $\mathrm{N}$-nitrosodimethylamine, 2-naphthylamine, and 4-aminobiphenyl are 52,39, and 31 times higher, respectively, in sidestream smoke than in mainstream smoke. ${ }^{42}$ On the other hand, the nicotine concentration in sidestream smoke is only 2.7 times higher than that in mainstream smoke. ${ }^{42}$ Thus, although cotinine levels in smokers may be almost entirely attributable to active smoking, passive smoking may contribute substantially to overall exposure to carcinogenic and other toxic components of tobacco smoke. ${ }^{46}{ }^{47}$ Under conditions of heavy workplace ETS exposure, smokers may inhale a daily dose of benzo(a)pyrene equivalent to that obtained by actively smoking $11 / 2-2$ packs of cigarettes, ${ }^{48} 49$ and a daily dose of ammonia and pyridine equivalent to that obtained by smoking $21 / 2$ packs of cigarettes. ${ }^{46} \mathrm{~A}$ one packper-day smoker who is exposed to ETS under these conditions could conceivably obtain a higher dose of these toxins from passive smoking than from active smoking. Another possible explanation for increased acute health effects among smokers exposed to ETS is that the people they live and work with, who are also being exposed to ETS, have more respiratory illnesses, thus increasing the likelihood that the smoker will be exposed to and develop these illnesses.
This study has several limitations. One is related to sample size. Even though the survey had almost 44000 participants, only $21.2 \%$ of non-smokers reported exposure to छTS and only $11.1 \%$ of current smokers reprorted no exposure to ETS. These low rates, infonjunction with several infrequent outcom $\vec{f}$ that we were evaluating, resulted in wide gुnfidence intervals. For example, to detecE a $20 \%$ increase in the incidence of chronic Eardiovascular disease exacerbations am商g nonsmokers (from $2.0 \%$ to $2.4 \%$ ) with क्षेpower of 0.80 and a $95 \%$ confidence interval, we would have needed more than 66000 non-s $\vec{P}$ okers in the study. To detect a similar increase among smokers, we would have needed nowre than 112000 current smokers.

ते

Another limitation in this analysis is the measure of workplace exposure, wich was limited to currently employed adfalts who worked in a specific type of work environment. This restriction led to the series of questions on workplace exposure being asked of $25 \%$ of the survey sample and only a\$out $50 \%$ of current workers. Workers who zivere not asked about worksite ETS exposurepincluded those who worked in one building with no regular work area, those who trapelled to different worksites, and those who wgrked in a motor vehicle. Furthermore, amon@ subjects asked about workplace exposure to ES, about $15 \%$ reported exposures. This glevel of exposure can be contrasted with exposures of $52-70 \%$ in a recent European study. ${ }^{40}$ Results from previous rese shown that people who have no regullar work area are twice as likely to report ETSExposure as are people working in a private office. ${ }^{16}$

Another problem with this of survey's evaluation of workplace exposures to ETS is that these exposures are probablo underreported. Workers were asked onlyo whether their immediate work area was smoge-free or not. Thus, smokers who are not aflowed to smoke at their worksite might be exposed to ETS in other indoor or outdoor designated smoking areas. ${ }^{39}$

We did not have biochemical measures of ETS exposure or primary smoking such as measurements of cotinine in strum or urine. ${ }^{1150}$ Previous studies have shown that misclassification of subjects' self-reported smoking status can occur. ${ }^{12}$ \$1 \$ack of biochemical measures also meant thatwwe were unable to validate ETS exposures. Flthough another nationally representative hudy has demonstrated that people reporting Exposures $^{2}$ generally have higher serum cotininge levels than people not reporting such exposures, ${ }^{11}$ self-reported ETS exposures do not nळ్cessarily correlate with serum or urine fevels of cotinine. ${ }^{49}{ }^{50}$ People can be exposed to ETS in places other than their homes or workplaces, such as stores or restaurants; the 19 g 1 NHIS did not ask about these potential exposure sites and this is probably why our overa rate of exposure to tobacco smoke of $42.8 \%$. $100 \%$ of current smokers and $21.2 \%$ of current non-smokers) is much lower than the exposure rate of $89 \%$ as indicated by measurable 
cotinine levels in a recent nationally representative study. ${ }^{11}$

We also do not have data on the amount of ETS that subjects were exposed to or whether they had exposures before the two weeks asked about in the survey. In this database, daily exposures in the home to one cigarette would be counted the same as daily exposure to 40 cigarettes. NHIS surveys subsequent to the 1991 survey asked about intensity of exposure. Similarly, workplace exposures, which were not asked of all workers, were also not quantified. We did not attempt to examine dose-response relationships in this analysis because we did not have good data on intensity or duration of exposure. It is possible that people reporting less than daily exposure to ETS had higher levels of exposure than those reporting daily exposures. Another study of ETS exposure in adults, which had data on hours of exposure daily, years of exposure, and number of smokers exposed, was able to demonstrate a dose-response relationship for respiratory symptoms such as wheeze, dyspnoea, and bronchitis symptoms. ${ }^{40}$

Another limitation of our study is that we could not validate the presence of diseases, the accuracy of the diagnoses, or the accuracy with which respondents reported their health status or morbidity. It is possible that people who smoke or are exposed to ETS simply report more problems than non-smokers or people who are not exposed to ETS. ${ }^{52}$ Conversely, a positive response bias, in which people who have a disease, such as asthma, are more likely to notice and report ETS exposure, is also possible. Our measure of chronic disease exacerbations, which included physician visits, may have resulted in the misclassification of some people who merely had routine, scheduled physician visits unrelated to any worsening of their chronic disease.

A final limitation of our analysis is that we could not include all potential confounders in our models. Recent studies have shown that people exposed to ETS may have poorer diets than people without such exposure. ${ }^{53}{ }^{54}$ Other confounders we could not control for in this analysis included workplace exposures to other agents causing health effects, outdoor air pollution, familial history of respiratory or cardiac disease, and past exposure to ETS.

Despite these limitations, this study demonstrates that never-smoking adults exposed to ETS report more morbidity than adults not exposed to ETS. ETS exposure can be reduced in worksites and other public areas through corporate and public policy as well as through educational efforts, and ETS has been eliminated in many of these areas; however, educating people about the dangers of ETS is the principal way to reduce ETS exposures in homes.

1 US Environmental Protection Agency. Respiratory health effects of passive smoking: lung cancer and other disorders. Washington, DC: Environmental Protection Agency, 1992. (Publication EPA $/ 600 / 6-90 / 006 \mathrm{~F}$.

2 Dockery DW, Ware JH, Spiro A, Speizer FE, Ferris BG Passive smoking, gas cooking, and respiratory health of children living in six cities. Am Rev Respir Dis 1984 129:366-74.
3 Ogston SA, Florey CduV, Walker CM. Association of infant alimentary and respiratory illness with parental smoking and other environmental factors. $\mathcal{F}$ Epidemiol Community Health 1987;41:21-5.

4 Wright AL, Holberg C, Martinez FD, Taussig LM Relationship of parental smoking to wheezing and nonwheezing lower respiratory tract illnesses in the first year of life. Am 7 Epidemiol 1989;129:1232-46.

5 Ehrlich R, Kattan M, Godbold J, et al. Childhood asthm and passive smoking. Urinary cotinine as a biomarker of exposure. Am Rev Respir Dis 1992;145:594-9.

6 Jindal SK, Gupta D, Singh A. Indices of morbidity and control of asthma in adult patients exposed to environmental tobacco smoke. Chest 1994;106:746-9.

$7 \mathrm{Xu} \mathrm{X,} \mathrm{Li} \mathrm{B.} \mathrm{Exposure} \mathrm{response} \mathrm{relationship} \mathrm{between} \mathrm{passive}$ smoking and adult pulmonary function. Am F Respir Crit Care Med 1995;151:41-6.

8 Robbins AS, Abbey DE, Lebowitz MD. Passive smoking and chronic respiratory disease in non-smoking adults. In f Epidemiol 1993;22:809-17.

9 Massey JT, Moore TF, Parsons VL, Tadros W. Design and estimation for the National Health Interview Survey, 1985-1994. Vital Health Stat 1989;2:1-4.

10 US Bureau of the Census. The current population survey. Washington, DC: US Government Printing Office, 1991

11 Pirkle JL, Flegal KM, Bernert JT, Brody DJ, Etzel RA, Maurer KR. Exposure of the US population to environ-
mental tobacco smoke. The Third National Health and mental tobacco smoke. The Third National Health and 1996;275:1233-40.

12 Bonham GS, Wilson RW. Children's health in families with cigarette smokers. Am f Public Health 1981;71:290-3.

13 Mannino DM, Siegel M, Husten C, Rose D, Etzel R. Environmental tobacco smoke exposure and health effects in children: results from the 1991 National Health Interview children: results from the 1991 National

14 US Centers for Disease Control and Prevention (CDC) Trends and recent patterns in selected tobacco-use behaviors-United States, 1900-1993. MMWR CDC Surveill Summ 1994;43:1-42.

15 Sandler DP, Helsing KJ, Comstock GW, Shore DL. Factors associated with past household exposure to tobacco smoke. Am $\mathcal{F}$ Epidemiol 1989;129:380-7.

16 Borland R, Pierce JP, Burns DM, Gilpin E, Johnson M, Bal D. Protection from environmental tobacco smoke in California: the case for a smoke-free workplace $\mathscr{f} A M A$ 1992;268:749-52.

17 US Centers for Disease Control and Prevention. State tobacco control highlights-1996. Atlanta, Georgia: Centers for Disease Control and Prevention, National Center for Chronic Disease Prevention and Health Promotion, Office on Smoking and Health, 1996. (CDC Publication No 099-4895.)

18 National Cancer Institute. Major local tobacco contro ordinances in the United States. Washington, DC: National Institutes of Health, 1993. (NIH Publication No 93 3532.)

19 Ostro BD. Estimating the risks of smoking, air pollution and passive smoke on acute respiratory conditions. Rish Analysis 1989;9:189-96.

20 Dayal HH, Khuder S, Sharrar R, Tribf N. Passive smoking in obstructive respiratory diseases in an industrialized urban population. Environ Res 1994;65:161-71.

21 Cummings KM, Zaki A, Markello S. Variation in sensitivity to environmental tobacco smoke among adult nonsmokers. Int f Epidemiol 1991;20:121-5.

22 Schwartz J, Zeger S. Passive smoking, air pollution and acute respiratory symptoms in a diary study of studen nurses. Am Rev Respir Dis 1990;141:62-7.

23 Diez-Roux AV, Nieto FJ, Comstock GW, Howard G, Szklo $M$. The relationship of active and passive smoking to carotid atherosclerosis $12-14$ years later. Prev Med carotid atheroscle

24 Howard G, Burke GL, Szklo $M$, et al. Active and passive smoking are associated with increased carotid wall thickness. The Atherosclerosis Risk in Communitie Study. Arch Int Med 1994;154:1277-82.

25 Hole DJ, Gillis CR, Chopra C, Hawthorne VM. Passive smoking and cardiorespiratory health in a general population in the west of Scotland. BMF 1989;299:423-7.

26 Glantz SA, Parmley WW. Passive smoking and heart disease: epidemiology, physiology, and biochemistry. Cir culation 1991;83:1-12.

27 Aronow WS. Effect of passive smoking on the cardiovascular and respiratory systems. In: US Department of Health Education, and Welfare. Proceedings of the third world conference on smoking and health, 2-5 fune 1975. Washington, DC: Public Health Service, 1975.

28 Aronow WS. Effect of cigarette smoking and of carbon monoxide on coronary heart disease. Chest 1976;70:514 8.

29 Aronow WS. Effect of passive smoking on angina pectoris N Engl f Med 1978;299:21-4.

30 Aronow WS. Aggravation of angina pectoris by two percen carboxyhemoglobin. Am Heart f 1981;101:154-157.

31 Aronow WS, Ferlinz J, Glauser F. Effect of carbon monoxide on exercise performance in chronic obstructive pulmonary disease. $A m \mp M$ M d 1977;63:904 8 .

32 Fontham ET, Correa P, Reynolds $P$, et al. Environmental tobacco smoke and lung cancer in nonsmoking women. A multicenter study. $\mathscr{F} A M A$ 1994;271:1752-9.

33 Akiba S, Kato H, Blot WJ. Passive smoking and lung cancer among Japanese women. Cancer Res 1986;46:4804-7. 
34 Buffler PA, Pickle LW, Mason TJ, Contant C. The causes of lung cancer in Texas. In: Mizell M, Correa P, eds. Lung cancer: causes and prevention. New York: Verlag Chemie cancer: causes and prevention.

35 Correa P, Pickle LW, Fontham E, Lin Y, Haenszel W. Passive smoking and lung cancer. Lancet 1983;2:595-7.

36 Geng G, Liang ZH, Zhang AY, Wu GL. On the relationship between smoking and female lung cancer. In: Aoki $M$ Hisamichi S, Tominaga S, eds. Smoking and health, 1987. Proceedings of the sixth world conference on smoking and health, 9-12 November 1987. Amsterdam: Elsevier, 1988:483-6.

37 Humble CG, Samet JM, Pathak DR. Marriage to a smoker and lung cancer risk. Am f Public Health 1987;77:598602 .

38 Koo LC, Ho JH, Saw D. Is passive smoking an added risk factor for lung cancer in Chinese women? $\mathcal{F}$ Exp Clin Cancer Res 1984;3:277-83.

39 Siegel M, Husten C, Merritt RK, Giovino GA, Eriksen MP. Effects of separately ventilated smoking lounges on the health of smokers: is this an appropriate public health policy? Tobacco Control 1995;4:22-9.

40 Luenberger $\mathrm{P}$, Schwartz J. Ackermann-Liebrich U, et al. Passive smoking exposure in adults and respiratory symptoms (SAPALDIA Study). Swiss study on air pollution and lung diseases in adults, SAPALDIA Team. Am $\mathcal{7}$ Respir Crit Care Med 1994;150:1221-8.

41 Danuser B, Weber A, Hartmann AL, Krueger H. Effects of a bronchoprovocation challenge test with cigarette sidestream smoke on sensitive and healthy adults. Chest 1993; 103:353-8.

42 US Department of Health, Education, and Welfare Smoking and health. A report of the Surgeon General, 1979. Rockville, Maryland: Public Health Service, Office on Smoking and Health, 1979. (DHEW Publication No (PHS) 79-50066.)

43 US Department of Health and Human Services. The health consequences of involuntary smoking. A report of the Surgeon General, 1986. Rockville, Maryland: Public Health Service, Centers for Disease Control, 1986. (DHHS Publication No (CDC) 87-8398.)

44 Adams JK, O'Mara-Adams J, Hoffmann D. Toxic and carcinogenic agents in undiluted mainstream smoke and sidestream smoke of different types of cigarettes. Carcinogenesis 1987;8:729-731.

45 Luceri F, Pieraccini G, Moneti G, Dolarg P. Primary aromatic amines from side-stream cigarete smoke are common contaminants of indoor air. Toxigl Ind Health 1993;9:405-13.

46 Guerin MR, Jenkins RA, Tomkins BA. The che्fistry of environmental tobacco smoke: composition and measurement. Chelsea, Michigan: Lewis Publishers, 1992.A

47 Hammond SK, Coghlin J, Gann PH, et al. between environmental tobacco smoke yposure and carcinogen-hemoglobin adduct levels in nonsmokers. Natl Cancer Inst 1993;85:474-8.

48 Cuddeback JE, Donovan JR, Burg WR. aspects of passive smoking. Am Ind Dyg Assoc $f$
1976;37:263-7.

49 Bridbord K, Finklea JR, Wagmer JK, et al. Hưfan exposure to polynuclear aromatic hydrocarbons. In: Freudenthal RI Jones PW, eds. Carcinogenesis. Volume 1: polyn mlear aromatic hydrocarbons: chemistry, metabolism, and carcinenesis. New York: Raven Press, 1976:319-24.

50 O'Conner TZ, Holford TR, Leaderer BP, Hämmond SK, Bracken MB. Measurement of exposure to fironmental tobacco smoke in pregnant women. Am F E Ejgdemiol 1995; 142:1315-21.

51 Tunstall-Pedoe H, Brown CA, Woodward M, $\overrightarrow{\text { TJ }}$ avendale R Passive smoking by self report and serum $C$ Gine and the prevalence of respiratory and coronary heart 8 isease in the Scottish heart health study. $\mathcal{F}$ Epidemiol Com mity Health 1995;49:139-43.

52 Friedman GD, Siegelaub AB, Dales LG. Cigatte smoking and chest pain. Ann Intern Med 1975;83:1-

53 LeMarchand L, Wilkens LR, Hankin JH, Hale NJ. Dietary patterns of female nonsmokers with and witmut exposure to environmental tobacco smoke. Cancer छuses Control 1991;2:11-6. (1)

54 Matanoski G, Kanchanaraksa S, Lantry D, Chang Y. Characteristics of nonsmoking women in NHGNES I and to spouses who smoke. Am f Epidemiol 1995;142:149-57

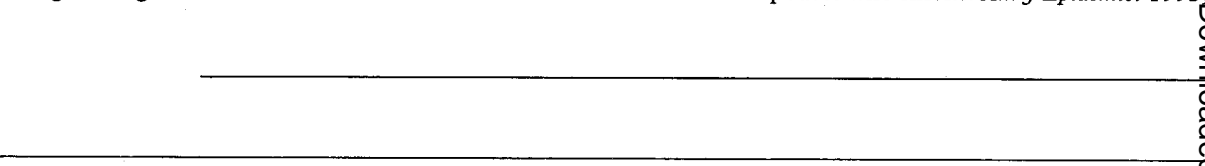

\section{Tobacco Control <http://www.tobaccocontrol.com>}

Visitors to the world wide web can now access Tobacco Control either through the BMJ Publishing Group's home page <http://www.bmjpg.com> or directly by using its individual URL < http://www.tobaccocontrol.com>. There they will find the following.

- Current contents list for the journal

- Contents lists of previous issues

- Members of the editorial board

- Subscribers' information

- Instructions for authors

- Details of reprint services.

There is also a longer version of the "Play It Again" section of Tobacco Control that was published in the Winter 1996 issue of the journal, cataloguing tobacco-related quotes made during the 1996 United States presidential campaign.

A hotlink gives access to:

- BMJ Publishing Group home page

- British Medical Association web site

- Online books catalogue

- BMJ Publishing Group books

The web site is at a preliminary stage and there are plans to develop it into more sophisticated site. Suggestions from visitors about features they would like to see ame welcomed. They can be left via the opening page of the BMJ Publishing Group site or, aitfernatively, via the journal page, through "About this site".

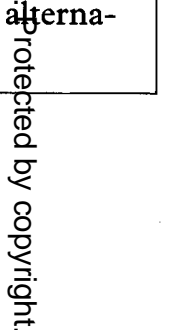

